\title{
A DATABASE SYSTEM FOR SMART SUSTAINABLE ISLANDS INDEX APPLICATION
}

\author{
Vassilios C. Moussas ${ }^{1,2}$, Dimos N. Pantazis ${ }^{1, *}$, Argyrakis Panagiotis ${ }^{1}$ \\ ${ }^{1}$ Research Group SOCRATES (Society for Organizations, Cartography, Remote sensing/Road design and Applications using \\ Technology/Transport engineering on Earth and Space), Dept. of Surveying \& Geoinformatics Engineering, \\ School Engineering, University of West Attica, Greece - *dnpantaz@otenet.gr, \\ ${ }^{2}$ Dept. of Civil Engineering, School Engineering, University of West Attica, Greece -vmouss@uniwa.gr,
}

\section{Commission VI, WG VI/4}

KEY WORDS: Smart Sustainable Cities, Smart Sustainable Islands, Island's Smartification, Sustainability Index, Smart Islands Initiative, SSI, $S^{2} I^{2}$, Intelligent Island

\begin{abstract}
:
The paper presents the application of an islands' smartification and sustainability index the Smart Sustainable Islands Index or $\mathrm{S}^{2} \mathrm{I}^{2}$. In addition to the classic parameters, the index is designed to include and emphasize specific parameters of the islands that are not usually found or they are less important in a mainland city. The structure and parameters of the index are presented and compared to other initiatives A database with a corresponding web page has been created in order to collect data from the islands for their index calculation. The database structure and relationships are presented, as well as, the user interaction and data collection forms. After the online system finalization, each island in Greece, Europe, or in the World will have the possibility to submit the required information \& data and will be able to see the graphic representation of the results and the rank of the island in terms of smartification and sustainability. The fully functioning system is expected to support significantly an islands' effort for a smarter, greener \& sustainable development.
\end{abstract}

\section{INTRODUCTION}

The Smart Sustainable Islands Index $\left(\mathrm{S}^{2} \mathrm{I}^{2}\right)$ was created in an attempt to assess and quantify the progress and the achievements on the way towards smarter, greener \& sustainable islands. After the theoretical development of $\mathrm{S}^{2} \mathrm{I}^{2}$ by the S.O.C.R.A.T.E.S Lab (Pantazis and al. 2017) the data requirements for the index calculation have been finalized. In order to demonstrate a practical result of our approach we created a database related to the index, with a dedicated web page for the data collection and the index calculation of the islands.

In this paper we present the methodological steps followed in order to develop the proposed system, its compatibility to relevant developed schemes by the United Nations, and how it will monitor the "smartification" and "sustainability" of islands via a series of data and parameters calculations.

Following this introduction we present a literature review of smart sustainable cities and islands index (paragraph 2). In paragraph 3 we present the $S^{2} I^{2}$ index structure. Paragraph 4 presents the database design and the fields and the relations of the parameters which constitute the $\mathrm{S}^{2} \mathrm{I}^{2}$. Paragraph 5 presents the database and GUI tools developed. The sixth paragraph introduces the processes of data collection for the system and the seventh paragraph shows indicative examples of the system. Finally, conclusions and perspectives of our work are presented in paragraph eight.

\footnotetext{
* Corresponding author
}

\section{PREVIOUS WORK AND OTHER INDEXING SYSTEMS}

A large number of different index sets on sustainable and/or smart cities can be found in the literature, published by various states, organizations, companies, or, interest groups such as: the UN prosperity index [UN 2016], the VUT smart cities ranking [VUT, 2007], Ericsson networked society city index [Ericsson 2014], ISO index system of smart city [ISO 2015], ITU: ICT development index [ITU 2015], etc.

\subsection{Smart Sustainable Cities (SSC) Indices}

A comparative analysis of 19 different sets was presented in 2015, by the International Telecommunication Union (ITU) and their Focus Group on Smart Sustainable Cities (SSC) [ITU 2015]. Their collection of KPIs was further extended in cooperation with many international \& UN organizations, to cover the recent advances and results, and, to create a more universal set of KPIs through their United for Smart Sustainable Cities (U4SSC) project [ITU 2017]. The U4SSC KPIs have been developed to provide cities with a consistent and standardised method to collect data and measure performance and progress to becoming a smarter city and a more sustainable city, and, help them achieving the UN Sustainable Development Goals (SDGs).

In the above UN developed scheme, each indicator forms a part of a holistic view of a city's performance in three dimensions; Economy, Environment and Society \& Culture. Within each dimension, there are sub-dimension that focus on more specific areas of performance and Progress. Sub-dimensions are divided in categories which include groups of indicators that provide a more in-depth view on a specific domain. All indicators are also subdivided into Core and Advanced indicators. Core indicators 
are those that should be able to be reported on by all cities, while advanced indicators provide a more in depth view of a city on more advanced initiatives but they may be beyond the current capabilities of some cities to report or implement [ITU 2017].

The KPI wheel published by the authors of the current work in 2018 [Pantazis et al, 2018], is in accordance with the guidelines of the aforementioned UN initiative. The initiative also proposed a KPI naming \& numbering convention which will be followed in our present work. Our KPI wheel is shown in Figure 1, and its main five major categories clearly correspond to the three UN main directions, i.e., Economy (Economy ICT \& Infrastructure), Environment (Resources) and Society \& Culture (Quality of Life \& Society)

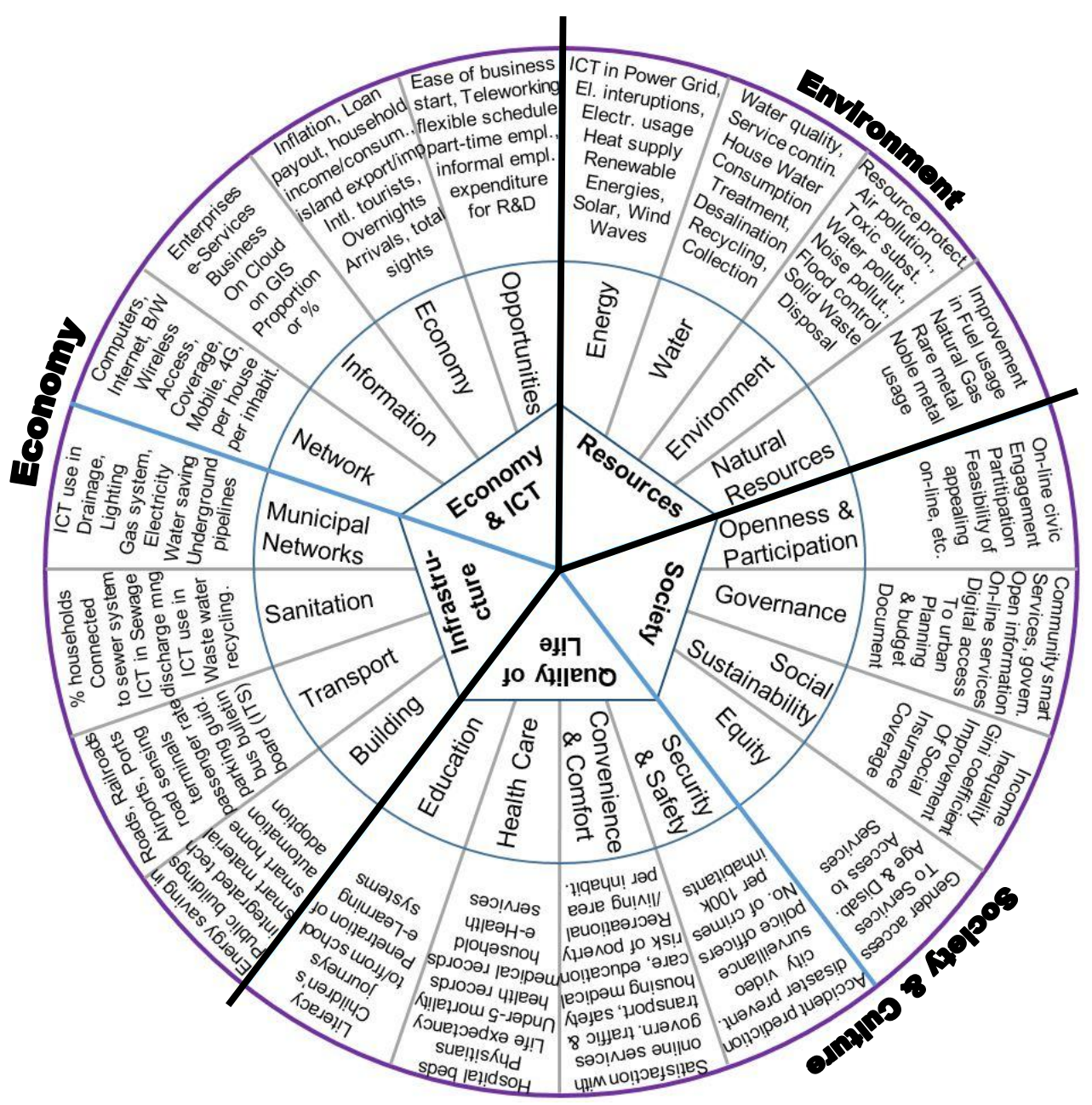

Figure 1. The KPI Wheel proposed by the authors [Pantazis et al, 2018], that also corresponds to the three UN main directions (in Bold).

\subsection{Smart Sustainable Islands}

In parallel to the UN initiatives an EU initiative was launched focusing on the "Smart Islands" [EU 2015]. According to the EU initiative, a "Smart Island" can be described as an island that creates local sustainable growth, offering a high quality of life to the local people, protecting natural resources and equipping public power supply and transport systems with smarter technology, as well as applying innovative governance methods or exploiting new funding schemes that are more innovative and participatory. The EU Smart Islands initiative suggests a new narrative for islands that calls for an integrated approach to the management of islands' natural resources and infrastructures; one that taps into European islands' potential to transform themselves into smart territories and improve the quality of life of island communities, all while helping the EU meet the goals it has set in a number of policy areas, including climate change mitigation and adaptation, circular economy, innovation, sustainable transport and mobility, blue growth, and the digital agenda [EU 2016].

In our work we followed the EU "smart island" initiative key factors: energy, transport, water, waste, governance, ICT and economy, and we developed a sort of guidelines and a start point for island's sustainable smartification [Pantazis et al, 2018]. In that earlier work it is also noted that an island constitutes an autonomous entity that must be seen and considered in a holistic way. Its "smartification" should not concern just a city or a village but the entire island. The particularities of the smartification of an island are related with its geographic characteristics, the isolation, the coastal lines, the tourism, the medical care, the infrastructure, the transport of goods, the education, the limited economic possibilities, etc. Therefore, the term smart sustainable island, in our context, has not only the same meaning with the term smart sustainable city, but in addition: A) it refers to the entire region of an island and not to a specific city, and, B) the term "sustainable" means that 
the entire island follows all the good practices to preserve the sustainable development.

It is obvious that a number of core key factors should be added to those proposed for mainland cities, and also, some special (or advanced) key factors should also be added in specific islands, (e.g. for Refugees, etc.). In order to help the islands' local municipalities, implement their steps towards their island smartification and sustainability, and to measure their progress, a set of KPIs for the Smart Sustainable Islands Index was designed, the $S^{2} I^{2}$. Following its development, an interactive tool was also required to enable an easy and remote access to the $\mathrm{S}^{2} \mathrm{I}^{2}$ index by the island's authorities. The proposed index and the corresponding tool will be presented in more detail in the following sections.

\section{THE $S^{2} I^{2}$ DESCRIPTION}

The main objective of this work is the on line implementation of an island smartification and sustainability index (i.e., the Smart Sustainable Island Index, or, $\mathrm{S}^{2} \mathrm{I}^{2}$ ). The aim of such an index is the quantification of the achievement of each insular municipality towards its smartification. The smartification index will also play the role of an alarm for each participating municipality for the increasing number of problems lacking smart solutions. The $\mathrm{S}^{2} \mathrm{I}^{2}$ index may also be used to measure the efficiency of the local authorities towards a greener and smarter island.

\subsection{Indicators Characteristics}

As proposed by [ITU, 2018], the major characteristics on the indicators should be: 1) Comprehensiveness: The set of indicators should cover all the aspects of SSC. 2) Availability: The KPIs should be quantitative and the historic and current data should either be available or easy to collect. 3) Simplicity: The concept of each indicator should be simple and easy to understand for the urban stakeholders. 4) Timeliness: This refers to the ability to produce KPIs with respect to emerging issues in SSC construction.

In addition, to ensure that the participating islands are able to collect their data and that the reported values are consistent, each indicator description should have at least the five detailed fields proposed by ITU, namely: 1) Rationale: the rationale for choosing it, 2) Interpretation: how it should be interpreted, 3) Benchmarking: what benchmarking trends are considered desirable, 4) Calculation: the methodology for calculating its value, and, 5) Source: potential sources of data. The KPIs may further be categorized by the type of the improvement they represent, i.e., if they describe a sustainability improvement measure/figure, a 'smartification' advancement, or, a general structural improvement/support, etc., as well as, by the type of information they provide, namely, Quantitative or Qualitative.

A sample description of a typical and common indicator (e.g., Household Internet Access) is shown in the following Table 1.

\begin{tabular}{|l|l|}
\hline Field & Content \\
\hline Dimension & Economy \\
\hline Sub-Dimension & ICT \\
\hline Category & ICT-Network \\
\hline Name & Household Internet Access \\
\hline
\end{tabular}

\begin{tabular}{|l|l|}
\hline MV(s) & $\begin{array}{l}\text { Directly Measured Values: } \\
\text { 1. Total No. of HH } \\
\text { 2. No. of HH with Internet access }\end{array}$ \\
\hline Description & \% of households with Internet access \\
\hline Unit & Percentage \\
\hline Calculation & $\begin{array}{l}\text { = No. of HH with Internet access / } \\
\text { Total No. of HH * 100 }\end{array}$ \\
\hline Sources / DBs & List of sources \& providers \& Links \\
\hline $\begin{array}{l}\text { Rationale } \\
\text { Interpretation } \\
\text { Benchmarking }\end{array}$ & $/$ \\
\hline Reference(s) & ITU - U4SSC (proposed by/Link) \\
\hline
\end{tabular}

Table 1. Sample list of an indicator description and detailed information

\subsection{The Overall $\mathrm{S}^{2} \mathrm{I}^{2}$ Index Structure}

The developed $\mathrm{S}^{2} \mathrm{I}^{2}$ index tree presented in this work is based on the following structure (from the top overall index, down to the single measured value):

1. Overall $\mathrm{S}^{2} \mathrm{I}^{2}$ index

2. $\mathrm{S}^{2} \mathrm{I}^{2}$ Dimension (or UN Major Dimension)

3. Sub-Dimensions (per Dimension)

4. Categories (per Sub-dimension)

5. KPIs (per Category) (Core \& Advanced Indicators)

6. Composing Values per KPI (Directly Measured Values - MVs)

The values from the lower levels are quantified, normalized, summarized and/or weighted summed to produce the composite values of the upper levels.

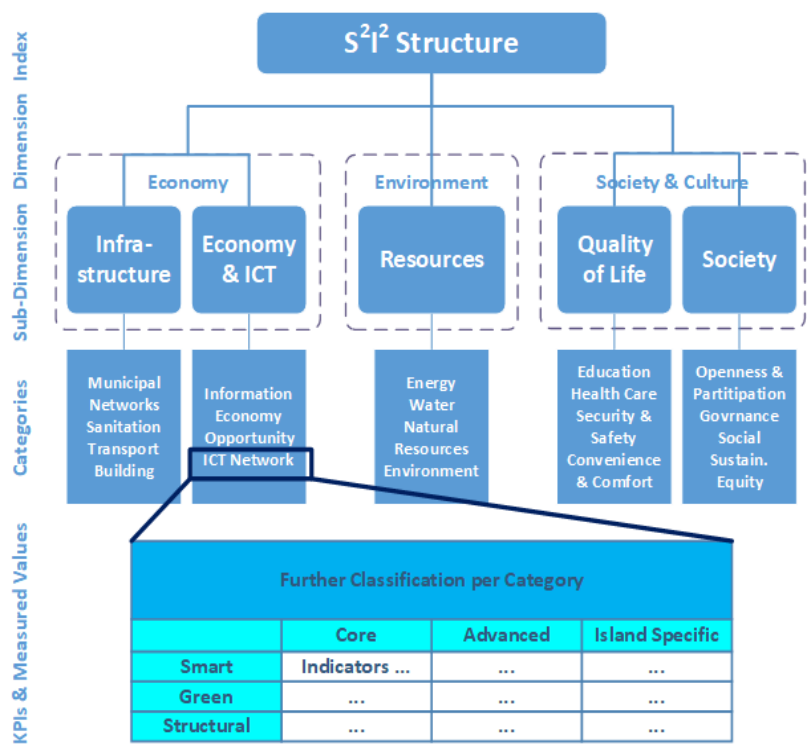

Figure 2. The proposed $S^{2} I^{2}$ Index Structure

\subsection{Islands' Specific indicators}

The proposed $\mathrm{S}^{2} \mathrm{I}^{2}$ index incorporates a number of indicators that are more important for the island cases and usually not found or less important for continental cities. The list of island Specific Indicators is not yet exhaustive as the index implementation will reveal any other required indicators or values, that will apply specifically on islands or only on specific 
islands. A sample list of island specific indicators follows in Table 2 .

\begin{tabular}{|l|l|}
\hline Category & Sample of Island Specific Indicators \\
\hline Economy & $\begin{array}{l}\text { Island export/import of goods \& food } \\
\text { ratios, Importance as tourist location (total } \\
\text { sights, overnights), Overnights per year per } \\
\text { resident, International tourists (arrivals per } \\
\text { resident)... }\end{array}$ \\
\hline Energy & $\begin{array}{l}\text { \% of Locally (island) produced renewable } \\
\text { energy, ... }\end{array}$ \\
\hline Water & $\begin{array}{l}\text { \% of Water desalination, \% of Imported } \\
\text { Water, ... }\end{array}$ \\
\hline Environment & $\begin{array}{l}\text { \% of ICT means used for Sea pollution } \\
\text { monitoring, ... }\end{array}$ \\
\hline Transport & $\begin{array}{l}\text { \% of Port/Airport coverage of High/Low } \\
\text { seasons demands, \% of Port/Airport } \\
\text { availability due to weather, Air/Sea } \\
\text { connections frequency to mainland per day, } \\
\text { Number of possible destinations \& } \\
\text { correspondences, ... }\end{array}$ \\
\hline Health & $\begin{array}{l}\text { \% of telemedicine coverage from mainland, } \\
\text { emergency transportation travel-time, ... }\end{array}$ \\
\hline
\end{tabular}

Table 2. Sample of island-specific indicators added to the typical city KPIs by the proposed $\mathrm{S}^{2} \mathrm{I}^{2}$.

\section{THE DATABASE DESIGN}

The database design is based on the entities of figure 1 . This means that starting from the central entity of the database which is the island; we relate it with the five entities (Dimensions) of the inner circle of the figure 1: Economy \& ICT, Resources,
Society, Quality of Life, Infrastructure. The relation diagram for the five entities of the inner circle is shown in figure 3.

Each one of those entities is related with the entities of the second circle (Categories): e.g. the entity Economy is related with the following entities: Opportunities, Economy, Information, ICT Network. Finally, each one of those entities is related with the correspondent entities of the last circle (Indicators \& MVs) of figure 1, which are, e.g. for the entity information, the following: Enterprises with e-services and Business on Cloud/on GIS, (Proportion of or \%), etc. (figure 4)

\section{THE DATABASE AND GUI DEVELOPMENT}

The database development was implemented in MySQL [Axmark, D., \& Widenius, M. 2015], a robust and open source solution. The need for a web-based solution, rather than single client software, was clear because the data for our database were going to be collected through several islands authorities which are geographically spread around the Greece. In addition, given the fact that the authorities are going to use a variety of web browser and Operating Systems, we need a system independent database. The Graphic User Interface is developed with the use of HTML5 and CSS, in addition we use specific JavaScript scripts for graphic representation and Ajax and PHP to get specific filtered data from MySQL. The web application was served through NGINX [Rahul Soni. 2016] load balanced server to avoid hardware load balancer and to assure a flawless web experience to our users. Interactive Maps and Spatial representation were made with the use of open-source leaflet JavaScript library.

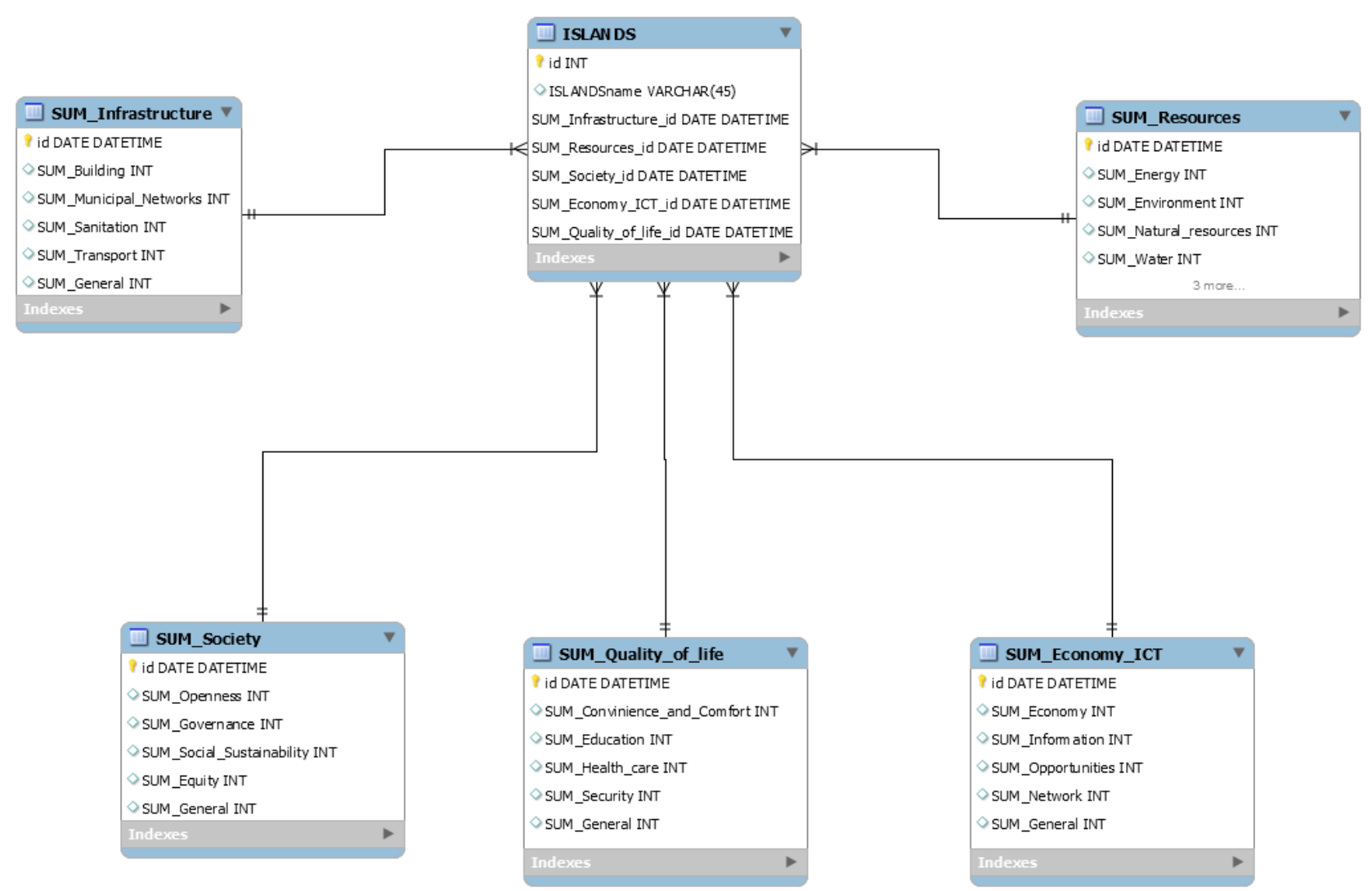

Figure 3. Relation diagram for the five entities of the inner circle of the figure 1: Economy \& ICT, Resources, Society, Quality of Life, Infrastructure 


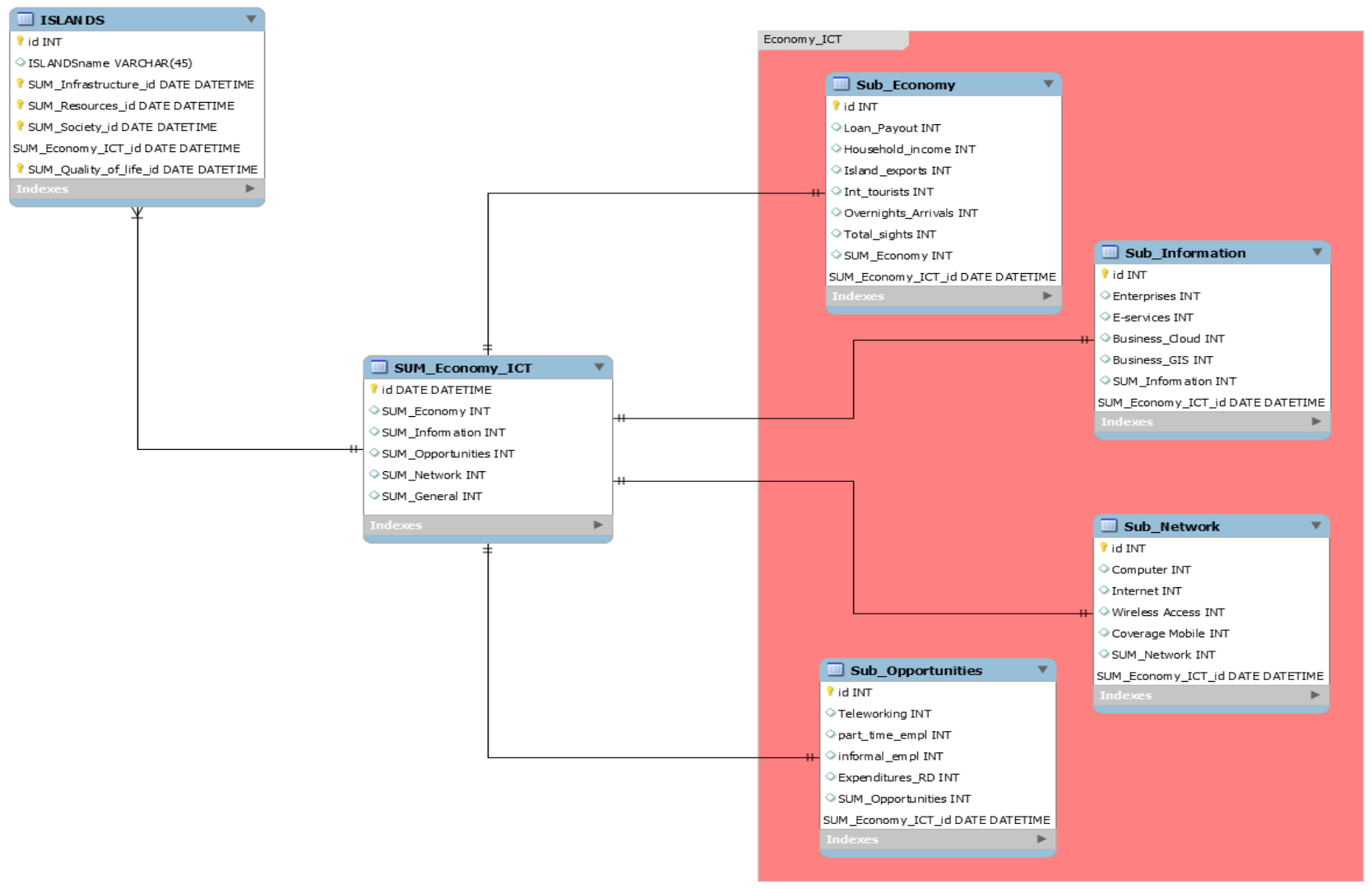

Figure 4. Relation between the entities of the second circle: e.g. the entity Economy is related with the following entities: Opportunities, Economy, Information, Network.

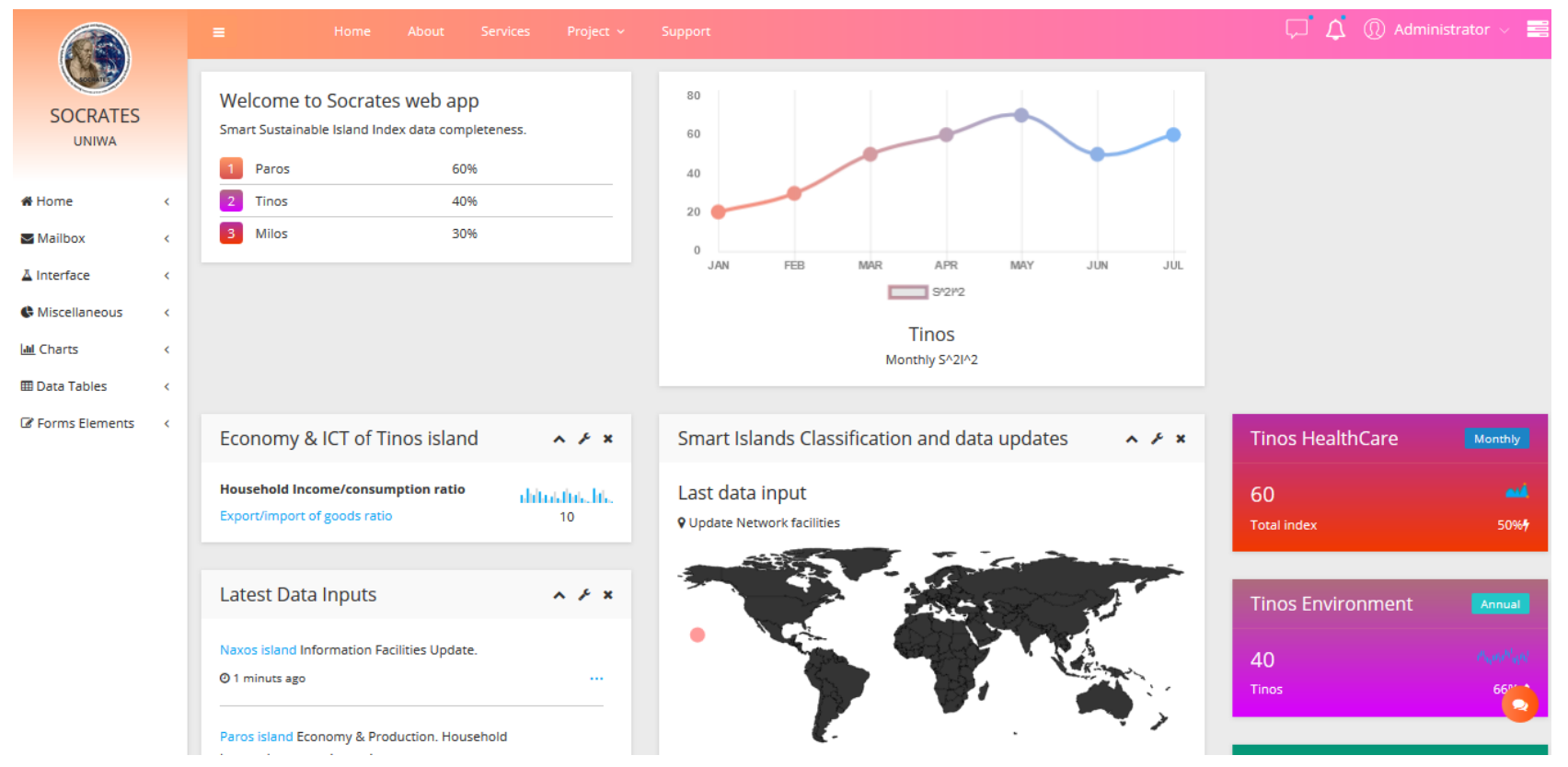

Figure 6. Sample webpage of the island's information dashboard. From left to right several info windows for e.g., Tinos island. 


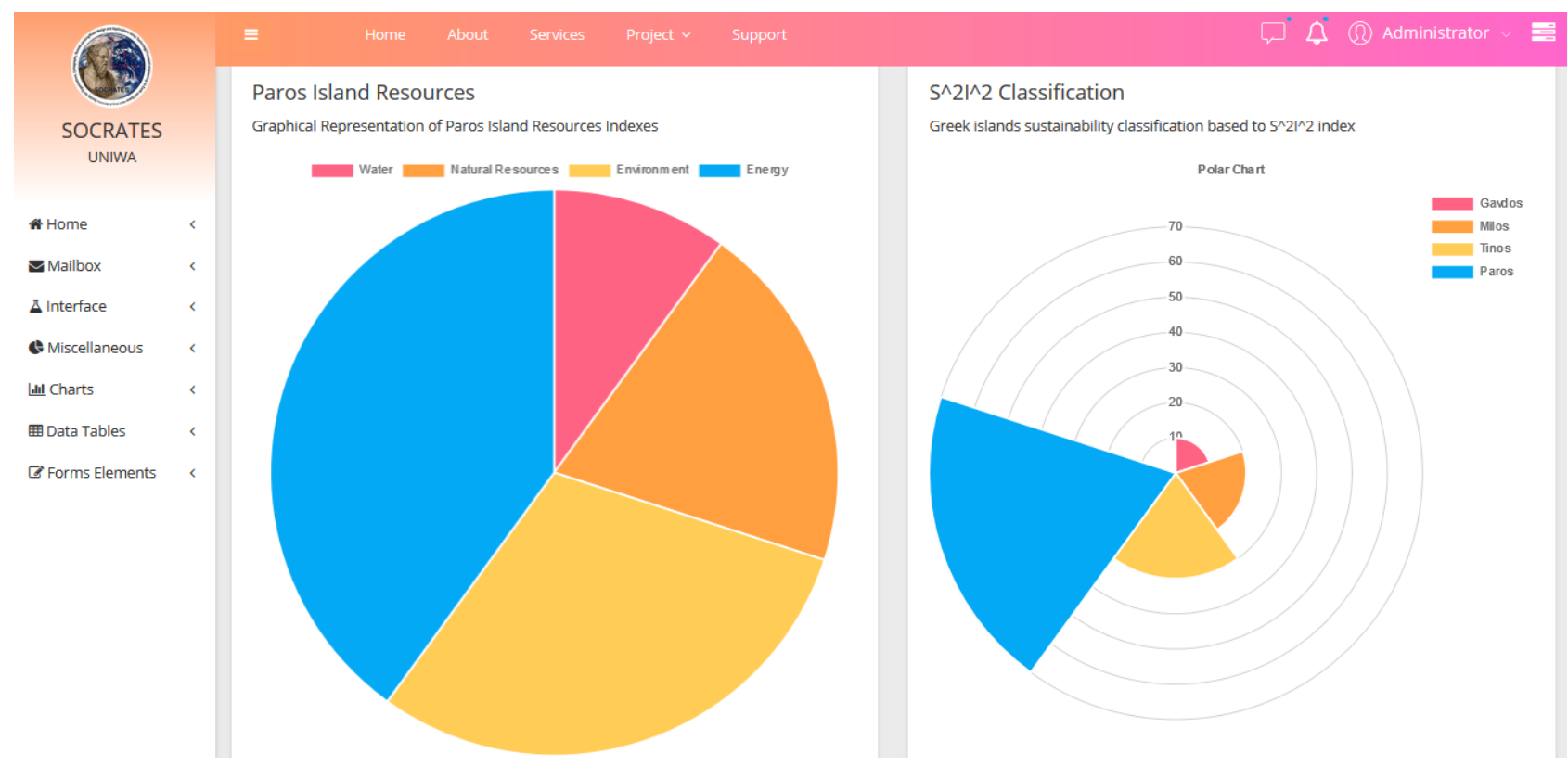

Figure 7. Two views of Paros island index, the sub-dimensions weighting (left) and the graphical comparison for sustainability to other 3 islands (right).

\section{DATA COLLECTION}

The $\mathrm{S}^{2} \mathrm{I}^{2}$ [D. N. Pantazis et al. 2017] calculation is based on the data collected for a large number of island parameters. Those data (parameters values) are the inputs provided by the local authorities of the islands. A special web application was made for the data collection with the use of Google Forms. The local authorities fulfil specific questionnaires available through a secured login page with a personalized username and password for each individual stakeholder. The questionnaire values are transferred to the system database (fig.5). This data insertion from questionnaire to MySQL database is achieved with a special plug-in connector built by Google.

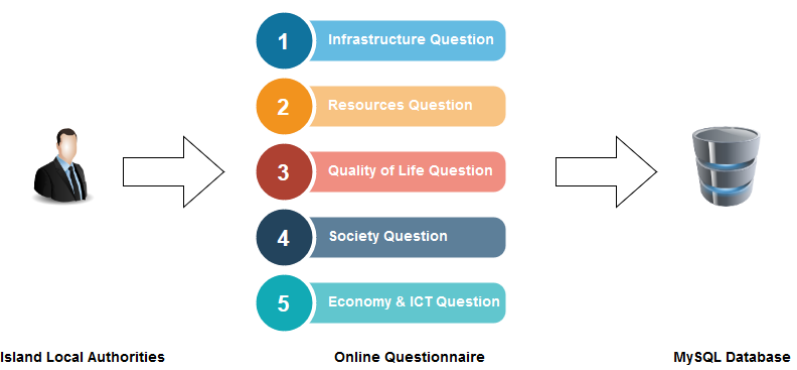

Figure 5. Island local authority data insertion and transfer to the system database.

\section{APPLICATION EXAMPLES}

A general application example concerning the data collection is shown in figure 6 and figure 7. Three island Paros, Tinos, Milos (fig.6) sent data (not actual data, only for demonstration purposes) to the web application. The Tinos island data concerning sustainability and smartification are being processed and shown in several windows/forms, such as, the Healthcare index, the Environment monitoring and the Information facilities.
The data update automatically each time the local authorities' updates are inserted through questionnaire new submissions. Several indexes like Energy, Water etc., are presented in a chart web page (figure 7 left) where specific islands indexe dimensions are shown in pie charts. In addition comparative charts between islands can be shown, e.g., the total sustainability classification of index $S^{2} I^{2}$ for several islands that is calculated with multiple MySQL queries from web application and plotted in a polar chart (figure 7 right).

\section{CONCLUSIONS AND PERSPECTIVES}

\subsection{Perspectives}

In the near future we will continue and complete the theoretical work concerning the $\mathrm{S}^{2} \mathrm{I}^{2}$ index development with the following objectives:

a. To identify different levels of the index application according to the data availability (core, advanced, specific, etc.)

b. To identify and calculate different weights (even for the same parameter) of the index according to the specific characteristics of the island e.g., the size, the population of the island, or its distance from mainland.

c. To identify the importance of the index parameters and personalize them to the island identity, etc.

We also schedule to identify and measure the difficulties of the data collection in order to create alternative, redundant and/or more reliable solutions of island data collection.

\subsection{Conclusions}

An enhanced Smart Sustainable Islands Index $\left(\mathrm{S}^{2} \mathrm{I}^{2}\right)$ was developed compatible to the UN initiative and enriched with island specific parameters. In order to make it accessible to all interested parties, an online database system concerning the data 
for the $S^{2} I^{2}$ index calculation has been developed. The system gives the possibility to the local authorities of islands (after registration) to introduce their data related to their smartification and sustainability (according to the $\mathrm{S}^{2} \mathrm{I}^{2}$ index) and obtain an estimation of their situation and trend, regarding the targets and other islands. The system is initially fed with the COTRIS project partners data and with the finalization of the test phase it will be open for registration to all islands. The $\mathrm{S}^{2} \mathrm{I}^{2}$ online system is expected to support significantly an islands' effort for a smarter, greener \& sustainable development. Similar on line \& open systems do not exist yet, in our knowledge.

\section{REFERENCES}

Axmark, D., Widenius, M., 2015. MySQL 5.7 Reference Manual. Redwood Shores, CA: Oracle. Link: dev.mysql.com/doc/refman/5.7/en/index.html [online] accessed 12/07/2019.

Ericsson, 2014. Networked Society City Index 2014. Link: https://www.ericsson.com/mediacdn/4a20f9/siteassets/news/2014/11/networked-society-cityindex-2014.pdf [online] accessed 12 /07/2019).

EU, 2015. Smart Islands Project - EESC initiative. Link: www.eesc.europa.eu/en/our-work/publications-other-

work/project/smart-islands-project [online] accessed $12 / 07 / 2019$

EU, 2016. Smart Islands Projects and Strategies. Issued from the $1^{\text {st }}$ European Smart Islands Forum, June 2016, Athens, Greece, Friedrich-Ebert-Stiftung, ISBN 978-618-81633-6-2.

ISO, 2015. Index system of smart city, ISO/TS 37151, Smart community infrastructures - Principles and requirements for performance metrics Link: www.iso.org/standard/61057.html [online] accessed 12/07/2019.

ITU-T FG-SSC, 2015. Key performance indicators definitions for smart sustainable cities, International Telecommunication Union, Focus Group on Smart Sustainable Cities, Technical Report, Feb 2015. Link: www.itu.int/en/ITU-T/focusgroups/ssc/ Documents/website/web-fg-ssc-0270-r3-KPIs_definitions.docx [online] accessed 12/07/2019.

ITU-U4SSC, 2017. Collection Methodology for Key Performance Indicators for Smart Sustainable Cities, United for Smart Sustainable Cities, ISBN: 978-92-61-25231-1, Link: itu.int/go/U4SSC [online] accessed 12/07/2019.

Pantazis, D. N., Moussas, V. C., Murgante, B., Daverona, A. C., Stratakis, P., Vlissidis, N., Kavadias, A., Economou, D., Santimpantakis, K., Karathanasis, B., Kyriakopoulou, V., Gadolou, E., 2018. Smart Sustainable Islands vs. Smart Sustainable Cities, ISPRS Ann. Photogramm. Remote Sens. Spatial Inf. Sci., IV-4/W3, 45-53, doi.org/10.5194/isprs-annalsIV-4-W3-45-2017.

Rahul Soni, 2016. Nginx: From Beginner to Pro (1st ed.). Apress, Berkely, CA, USA.

UN-Habitat City prosperity index, 2016. Measurement of City Prosperity Methodology and Metadata. Link: unhabitat.org/wpcontent/uploads/2019/02/CPI-METADATA.2016.pdf [online] accessed 12/07/2019.
VUT, 2007. Smart cities Ranking of European medium-sized cities. Vienna University of Technology. Link: www.smartcities.eu/download/smart_cities_final_report.pdf [online] accessed 12/07/2019. 